\title{
Management of Patients with Acute Venous Thromboembolism: Findings from the RIETE Registry
}

\author{
Manuel Monreala, Carmen Suárezb, José A.G. Fajardoc, Raquel Barbad, \\ Fernando Uresandie, Reina Vallef, Pilar Rondóng and the RIETE investigators
}

aHospital Germans Trias i Pujol, Badalona, Spain; bHospital de la Princesa, Madrid, Spain; cHospital Clínico, Valladolid, Spain dFundación Alcorcón, Madrid, Spain; eHospital de Cruces, Bilbao, Spain; fHospital de Sierrallana, Cantabria, Spain; gHospital Severo Ochoa, Madrid, Spain

\section{Key Words \\ Venous thrombosis - Pulmonary embolism - \\ Treatment · Registry · Outcome}

\begin{abstract}
Guidelines for the treatment of venous thromboembolism (VTE) are mainly based on randomized controlled trials, but a number of patients with VTE are excluded from trials due to co-morbidities (i.e., recent bleeding, renal insufficiency, thrombocytopenia, abnormal prothrombin time or pregnancy). Thus, treatment regimens derived from clinical studies may not be suitable for all patient groups.

RIETE (Registro Informatizado de la Enfermedad TromboEmbólica) is a Spanish registry of consecutively enrolled patients with objectively confirmed, symptomatic acute VTE. We compared the clinical outcome during the first 3 months of therapy of VTE patients with at least one of the mentioned co-morbidities with that in patients without them.

Of 6855 patients enrolled up to February 2004, 1635 (24\%) had at least one reason to be excluded from clinical trials: recent bleeding (2.6\%); renal insufficiency $(13.6 \%)$; thrombocytopenia (2.5\%); abnormal prothrombin time $(9.1 \%)$ and pregnancy $(0.7 \%)$. During the 3-month follow-up period the rates of fatal pul-
\end{abstract}

\section{KARGER}

Fax +41613061234

E-Mail: karger@karger.ch

www.karger.com (c) 2004 S. Karger AG, Basel

1424-8832/04/0336-0330\$21.0/0

Accessible online at: www.krager.com/pht monary embolism (odds ratio: 3.3; 95\% Cl: 2.5-5.2); minor bleeding (odds ratio: 1.8; 95\% Cl: 1.3-2.2); major bleeding (odds ratio: $3.1 ; 95 \% \mathrm{Cl}$ : 2.3-4.1) and fatal bleeding (odds ratio: $4.1 ; 95 \% \mathrm{Cl}$ : 2.1-8.0) were significantly higher in patients with at least one of these co-morbidities than in the remaining 5220 patients.

The clinical outcome was significantly worse in patients with either recent bleeding, renal insufficiency, thrombocytopenia, abnormal prothrombin time, or pregnancy. The expanding RIETE database of "realworld" outcomes may lead to improved treatment of VTE, especially for those patients not usually included in randomized clinical trials.

Copyright (c) 2004 S. Karger AG, Basel

\section{Introduction}

Anticoagulant therapy is the treatment of choice for most patients with venous thromboembolism (VTE). The proceedings of the sixth American College of Chest Physicians (ACCP) Consensus Conference provide an extensive critical review of the literature related to the management of patients with VTE and lay the scientific groundwork for the standard of care, based largely on data from randomized controlled clinical trials [1,2]. However, a num-
Prof. Manuel Monreal, PhD

Servicio de Medicina Interna

Hospital Universitari Germans Trias i Pujol

08916 Badalona, Barcelona,Spain

E-mail: mmonreal@ns.hugtip.scs.es 
ber of patients are often excluded from clinical trials (for example due to pregnancy, renal insufficiency or high risk of bleeding). Thus, there is no evidence about what would be the best therapeutic approach for these patients.

The "Registro Informatizado de la Enfermedad TromboEmbólica" (RIETE) was initiated in March 2001 to record current clinical management of VTE within Spanish hospitals. Developed under the guidance of a scientific advisory committee comprising of leading physicians and scientists, the registry is a multicenter, observational study designed to gather and analyze data on treatment patterns and outcomes in patients with symptomatic VTE. In contrast to a randomized controlled trial, there is no imposed experimental intervention: management is determined solely by physicians. Data captured and reported in the registry will therefore reflect "real-world" approaches and outcomes in the treatment of VTE.

The aim of the present observational study using RIETE data was to evaluate the clinical outcomes of VTE patients with either recent bleeding, renal insufficiency, thrombocytopenia, abnormal prothrombin time, pregnancy, as compared to patients with none of them.

\section{Patients and Methods}

\section{Patient Entry Criteria}

Participating hospitals enroll all patients that meet predefined eligibility criteria. Patients are included if they have symptomatic, acute deep-vein thrombosis (DVT) or pulmonary embolism (PE), confirmed by objective tests (i.e. contrast venography, ultrasonography or impedance plethysmography, for suspected DVT; pulmonary angiography, lung scintigraphy or helical computed tomography scan, for suspected PE). Patients are excluded if they are currently participating in a therapeutic clinical trial or if they will not be available for a 3-month follow-up.

All patients provide informed consent to their participation in the study, according to the requirements of the ethics committee within each hospital. Data quality is monitored and documented, and a full data audit is performed at periodic intervals.

\section{Study Parameters and Endpoints}

The primary parameters recorded by the registry comprise details of each patient's clinical status, including any coexisting or underlying conditions, and the type, dose, duration and outcome (during the first 3 months of therapy) of antithrombotic treatment. Study endpoints are clinically recognized (and objectively confirmed) recurrences of VTE, major and minor bleeding complications [3], and death. Bleeding complications are classified as major or minor

Findings from the RIETE Registry according to the criteria by Doyle et al.: bleeding is classified as "major" if it was overt and was either associated with a decrease in the hemoglobin level of $20 \mathrm{~g} / \mathrm{L}$ or more, led to a transfusion of $2 \mathrm{U}$ of blood or more, or was retroperitoneal or intracranial. Bleeding is defined as minor if it was clinically relevant but did not meet the other criteria for major bleeding

\section{Use of the RIETE Study Database}

Although not intended to influence the routine management of patients participating in the registry, collated data from RIETE are available on the registry's website (www.riete.org) for use by physicians participating, and others in the field. An underlying or coexisting medical condition is selected from a drop-down list and data from the RIETE database are displayed, showing treatments, doses and outcomes of patients with similar clinical profiles. The user can thus compare different therapies and decide which is the most appropriate for their patient, based on previous "real-world" outcomes.

\section{Data Management and Confidentiality}

S \& H Medical Science Service is the coordinating center for the registry, with responsibility for all data management activities. Data for each patient are entered on a standard case report form and submitted to the coordinating center via the Internet through a secure website. The confidentiality of patient, physician and hospital data is protected prior to data submission by assigning a unique study number to each patient at enrollment, and by deleting or coding all other information that could identify a person or institution. Confidential electronic data are further protected by passwords and all paper copies of data and reports are stored in a secure facility.

\section{Current Findings}

This paper presents a sample of data extracted from the data of 6855 patients already enrolled in RIETE, comprising rates of minor and major bleeding and recurrent VTE associated with different antithrombotic therapies for some specific patient subgroups: an episode of major bleeding during the 30 days before VTE diagnosis; renal insufficiency (serum creatinine levels $>1.5 \mathrm{mg} / \mathrm{dl}$ ); thrombocytopenia $(<100,000 / \mathrm{mm} 3)$; abnormal prothrombin time $(<70 \%)$ or pregnancy. Odds ratios and corresponding 95 percent confidence intervals were calculated (Confidence Interval Analysis, version 2.0.0), and $\mathrm{p}<.05$ was considered as statistically significant. The significance of a number of clinical variables on the risk of either bleeding complications or $\mathrm{PE}$ events was tested by fitting bivariate proportional hazards models.

Pathophysiol Haemost Thromb 2003/2004;33:330-334 


\section{Results}

To date, 6855 patients have been enrolled in RIETE. Of them, 1635 (24\%) had at least one co-morbidity which would lead to them being excluded from most clinical trials. During the 3-month follow-up period there were no significant differences in the recurrence rate between patients with or without any of these conditions, but the rate of fatal PE was significantly higher in those with relevant co-morbidities (Table 1). Furthermore, patients with a relevant co-morbidity developed significantly more bleeding complications (minor, major or fatal bleeding complications), as depicted in Table 2. The odds ratio and 95\% confidence intervals for each event developing during the 3-month follow-up period appear in Table 3.

Table 1. Recurrence rate during the 3-month follow-up period in 6,855 consecutive patients with venous thromboembolism, according to the presence or absence of co-morbidities.

\begin{tabular}{llll}
\hline Co-morbidity & $\begin{array}{l}\text { Recurrent } \\
\text { DVT }\end{array}$ & $\begin{array}{l}\text { Recurrent } \\
\text { PE }\end{array}$ & $\begin{array}{l}\text { Fatal } \\
\text { PE }\end{array}$ \\
\hline Recent bleeding (N=180) & $10(5.5 \%)$ & $2(1.1 \%)$ & $6(3.3 \%)$ \\
Renal insufficiency (N=935) & $28(3.0 \%)$ & $18(1.9 \%)$ & $46(4.9 \%)$ \\
Abnormal PT (N=627) & $33(5.3 \%)$ & $9(1.4 \%)$ & $22(3.5 \%)$ \\
Thrombocytopenia (N=175) & $11(6.3 \%)$ & $1(0.6 \%)$ & $6(3.4 \%)$ \\
Pregnancy (N=48) & $1(2.1 \%)$ & 0 & 0 \\
& & & $66(4.0 \%)$ \\
Any of them (N=1,635) & $62(3.8 \%)$ & $28(1.7 \%)$ & $60(1.1 \%)$ \\
None (N=5,220) & $154(3.0 \%)$ & $104(2.0 \%)$ & 6 \\
\hline
\end{tabular}

DVT $=$ deep venous thrombsis

$\mathrm{PT}=$ prothrombin time

$\mathrm{PE}=$ pulmonary embolism

Table 2. Bleeding complications during the 3-month follow-up period in 6,855 consecutive patients with venous thromboembolism, according to the presence or absence of some co-morbidities.

\begin{tabular}{llll}
\hline Co-morbidity & $\begin{array}{l}\text { Minor } \\
\text { bleeding }\end{array}$ & $\begin{array}{l}\text { Major } \\
\text { bleeding }\end{array}$ & $\begin{array}{l}\text { Fatal } \\
\text { bleeding }\end{array}$ \\
\hline Recent bleeding (N=180) & $17(9.4 \%)$ & $12(6.7 \%)$ & $5(2.8 \%)$ \\
Renal insufficiency (N=935) & $56(6.0 \%)$ & $66(7.1 \%)$ & $17(1.8 \%)$ \\
Abnormal PT (N=627) & $29(4.6 \%)$ & $31(4.9 \%)$ & $12(1.9 \%)$ \\
Thrombocytopenia (N=175) & $8(4.6 \%)$ & $11(6.3 \%)$ & $3(1.7 \%)$ \\
Pregnancy (N=48) & 0 & 0 & 0 \\
Any of them $(\mathrm{N}=1,635)$ & $93(5.7 \%)$ & $92(5.6 \%)$ & $23(1.4 \%)$ \\
None $(\mathrm{N}=5,220)$ & $181(3.5 \%)$ & $100(1.9 \%)$ & $18(0.3 \%)$ \\
\hline
\end{tabular}

$\mathrm{PT}=$ prothrombin time

In patients with a recent episode of major bleeding $(n=218)$, major bleeding occurred in $4.5 \%$ receiving lowmolecular weight heparin (LMWH), 5.5\% receiving LMWH plus inferior vena cava filter (IVCF) and $4.5 \%$ receiving unfractionated heparin (UFH), as depicted in Table IV. Mean doses for each treatment option are provided. Major bleeding during long-term therapy occurred in 2
Table 3. Odds of developing symptomatic events during the 3-month follow-up period according to the presence or absence of a relevant comorbidity.

\begin{tabular}{lll}
\hline & Odds ratio (95\% CI) & P value \\
\hline Recurrent DVT & $1.30(0.95-1.77)$ & 0.089 \\
Recurrent PE & $0.86(0.55-1.33)$ & N.S. \\
Fatal PE & $3.62(2.50-5.23)$ & $<0.0001$ \\
Minor bleeding & $1.68(1.29-2.19)$ & $<0.0001$ \\
Major bleeding & $3.05(2.26-4.12)$ & $<0.0001$ \\
Fatal bleeding & $4.12(2.14-7.99)$ & $<0.0001$ \\
\hline
\end{tabular}

DVT = deep venous thrombosis

$\mathrm{PE}=$ pulmonary embolism

O.R. $(95 \% \mathrm{CI})=$ odds ratio $(95 \%$ confidence intervals $)$

Table 4. Clinical outcomes during both acute and long-term therapy in patients with recent major bleeding ( $<1$ month before VTE diagnosis).

\begin{tabular}{|c|c|c|c|}
\hline & $\begin{array}{l}\text { Major } \\
\text { bleeding }\end{array}$ & $\begin{array}{l}\text { Minor } \\
\text { bleeding }\end{array}$ & $\begin{array}{l}\text { Recurrent } \\
\text { VT }\end{array}$ \\
\hline $\begin{array}{l}\text { Acute therapy } \\
\text { LMWH (N=177) } \\
\text { Mean daily dose (IU) } \\
\text { LMWH + IVCF (N=19) } \\
\text { Mean daily dose (IU) } \\
\text { UFH (N=22) } \\
\text { Mean daily dose (IU) }\end{array}$ & $\begin{array}{l}8(4.5 \%) \\
7,438 \\
1(5.5 \%) \\
2,500 \\
1(4.5 \%) \\
24,000\end{array}$ & $\begin{array}{l}3(1.7 \%) \\
10,800 \\
0\end{array}$ & $\begin{array}{l}1(0.6 \%) \\
5,700 \\
0\end{array}$ \\
\hline $\begin{array}{l}\text { Long-term therapy } \\
\text { LMWH (N=84) } \\
\text { Mean daily dose (IU) } \\
\text { LMWH + IVCF (N=26) } \\
\text { Mean daily dose (IU) } \\
\text { AVK (N=63) }\end{array}$ & $\begin{array}{l}2(2.4 \%) \\
6,250 \\
1(3.8 \%) \\
5,000 \\
1(1.6 \%)\end{array}$ & $\begin{array}{l}5(6.0 \%) \\
8,380 \\
2(7.7 \%) \\
6,250 \\
3(4.8 \%)\end{array}$ & $\begin{array}{l}2(2.4 \%) \\
6,000 \\
1(3.8 \%) \\
4,000 \\
1(1.6 \%)\end{array}$ \\
\hline
\end{tabular}

LMWH = low-molecular-weight heparin

$\mathrm{UFH}=$ unfractionated heparin

IU = international units

IVCF = inferior vena cava filter

AVK = anti-vitamin $\mathrm{K}$ drugs

VTE $=$ venous thromboembolism

of the 84 patients treated with LMWH, 1 of the 26 patients receiving $\mathrm{LMWH}$ plus IVCF and in one of the 63 patients receiving vitamin $\mathrm{K}$ antagonists.

In patients with abnormal prothrombin time $(n=788)$ major bleeding occurred in $2.2 \%$ receiving low-molecular weight heparin (LMWH) and 6.7\% receiving unfractionated heparin (UFH), as depicted in Table V. Rates of major bleeding during long-term therapy $(n=622)$ were $0.9 \%$ with LMWH and $1.5 \%$ with vitamin $\mathrm{K}$ antagonists. 
Table 5. Clinical outcomes in patients with abnormal prothrombin time.

\begin{tabular}{|c|c|c|c|}
\hline & $\begin{array}{l}\text { Major } \\
\text { bleeding }\end{array}$ & $\begin{array}{l}\text { Minor } \\
\text { bleeding }\end{array}$ & $\begin{array}{l}\text { Recurrent } \\
\text { VT }\end{array}$ \\
\hline \multicolumn{4}{|l|}{ Acute therapy } \\
\hline LMWH (N=639) & $14(2.2 \%)$ & $7(1.1 \%)$ & $6(0.9 \%)$ \\
\hline Mean daily dose (IU) & 12,850 & 13,300 & 12,967 \\
\hline LMWH + IVCF (N=15) & $1(6.7 \%)$ & 0 & 0 \\
\hline Mean daily dose (IU) & 2,500 & & \\
\hline UFH (N=124) & $3(2.4 \%)$ & $2(1.6 \%)$ & 0 \\
\hline Mean daily dose (IU) & 25,133 & 31,000 & \\
\hline UFH + IVCF (N=10) & 0 & 0 & 0 \\
\hline \multicolumn{4}{|l|}{ Mean daily dose (IU) } \\
\hline \multicolumn{4}{|l|}{ Long-term therapy } \\
\hline LMWH (N=215) & $2(0.9 \%)$ & $5(2.3 \%)$ & $6(2.8 \%)$ \\
\hline Mean daily dose (IU) & 5,850 & 10,500 & 11,417 \\
\hline LMWH + IVCF $(\mathrm{N}=18)$ & $1(5.6 \%)$ & 0 & $1(5.6 \%)$ \\
\hline Mean daily dose (IU) & 5,000 & & 4,000 \\
\hline AVK $(N=389)$ & $6(1.5 \%)$ & $9(2.3 \%)$ & $11(2.8 \%)$ \\
\hline AVK + IVCF $(N=17)$ & 0 & 0 & $3(17.6 \%)$ \\
\hline
\end{tabular}

LMWH = low-molecular-weight heparin

$\mathrm{UFH}=$ unfractionated heparin

$\mathrm{IU}=$ international units

$\mathrm{IVCF}=$ inferior vena cava filter

$\mathrm{AVK}=$ anti-vitamin $\mathrm{K}$ drugs

VTE $=$ venous thromboembolism

\section{Discussion}

Physicians need to be aware of factors that influence a patient's response to anticoagulant therapy. Prognostic tools that give quantitative probabilities of adverse events, and are of practical value to physicians, are clearly required. A history of bleeding has consistently been shown to be predictive of major bleeding associated with antithrombotic therapy $[4,5]$ while the presence of a serious co-morbid condition, such as malignancy, liver or renal insufficiency [6-8] also predicts hemorrhagic events. The relationship between older age or pregnancy and anticoagulant-associated bleeding remains controversial [9-11].

Paradoxically, many of these high-risk patients are excluded from the randomized clinical trials upon which the recommendations for the treatment of VTE are based [1,2]. By contrast, the RIETE registry has already collected data on VTE treatment in many of these patient subgroups. Although patient numbers for many subsets within the RIETE database are currently small, numerical differences in outcomes such as those reported in the current paper suggest the possibility of clinically relevant treatment differences. The data also indicate that standard recommended therapy for VTE (UFH or LMWH during the acute phase followed by a vitamin $\mathrm{K}$ antagonist for at least 3 months) may not be optimal in some of these groups. Further, the risk of bleeding complications may not be directly dose-related in certain patient groups. More patients are needed to inves-

Findings from the RIETE Registry tigate fully these observations.

As the RIETE database grows, these apparent treatment differences will be clarified, providing physicians with outcomes data based on "real-world" data, rather than results of highly controlled clinical trials with restricted study populations. The database will provide information on the number of patients treated, the mean daily dosage of therapies and the frequency of associated patient outcomes (hemorrhagic events, recurrent VTE, death) in each instance. Data for different subgroups, including those with malignancies, older patients, and those with differing types and sites of bleeding will be analyzed separately by the website, allowing a simulation of many different therapeutic situations.

Although considerable change has already occurred in the field of medical informatics, its impact on clinical practice continues to grow. Clinical informatics provide access to the wealth of knowledge and experience gained in clinical practice, allowing management approaches to be optimized, providing enhanced patient outcomes and reduced costs [12-14]. The goal of RIETE is to improve the treatment of VTE through a better understanding of patient demographics, management, and in-hospital and post-discharge outcomes. It is currently planned that the registry will enroll at least 4,000 patients per year for a minimum of 3 years. This approach will provide an opportunity to observe temporal trends in clinical practices and patient outcomes.

Because RIETE is a prospective registry and not a randomized controlled trial, there is no single hypothesis from which to calculate the minimum sample size required. However, the large size of the planned cohort suggests that the study will provide valid data to answer many outstanding questions in VTE management. Recently the database has been translated into English, aimed to extend the registry to other countries, ultimately allowing physicians worldwide to use the database to select the most appropriate therapy and dosage for each of their patients.

\section{Acknowledgements}

We express our gratitude to Aventis Pharma for supporting this Registry with an unrestricted educational grant and "S \& H Medical Science Service" for their logistic and administrative support.

The project has been partially supported by Red Respira from the Insituto Carlos III.

Pathophysiol Haemost Thromb 2003/2004;33:330-334 


\section{Appendix: Members of the RIETE Group}

M.D. Adarraga (Jaén), J. Bugés, I. Canas, M. Monreal, E. Raguer, A. Raventós, C. Tolosa (Barcelona), J.I. Arcelus, I. Casado (Granada), R. Barba, I. Candel, J. del Toro, C. Fernández, J. Gutiérrez, P. Rondón, C. Suárez (Madrid), J.L. Beato (Albacete), A. Blanco, M.D. García, L. López, R.Tirado (Córdoba), J. Bosco, P. Gallego, M.J. Soto (Cádiz), J.M. Calvo (Badajoz), F.Conget (Zaragoza), M.C. del Río (Zamora), F. Gabriel, E. Grau, P. Román, J.A. Todolí (Valencia), F. García Bragado, A. Grau, S. Soler (Girona),
M.A. González, M.R. Gutiérrez, R. Otero (Sevilla), J.A. González -Fajardo (Valladolid), R. Guijarro, M. Guil, J.J. Martín, J. Trujillo (Málaga), L. Hernández (Alicante), R. Lecumberri, M. Rivero, A.L. Sampériz, G. Tiberio (Navarra), J.L. Lobo (Vitoria), I. López, S. Rubio (Asturias), A. Maestre, (Alicante), J. Montes (Vigo), J. Moreno (Segovia), J.A. Nieto (Cuenca), M.A. Page (Murcia), J.L.Pérez-Burkhardt (Tenerife), J. Portillo (Ciudad Real), R. Rabunal (Lugo), J.F. Sánchez (Cáceres), A. Sánchez (Salamanca), J.A. Torre (A Coruna), F. Uresandi (Bilbao), R. Valle (Cantabria), and F. Pajuelo (Medical Department, Aventis Pharma, Madrid).

\section{References}

Hyers TM, Agnelli G, Hull RD, Morris TA, Samama M, Tapson V, Weg JG. Antithrombotic therapy for venous thromboembolic disease. Chest 2001;119: 76S-93S.

2 Ansell J, Hirsh J, Dalen J, Bussey H, Anderson D, Poller L, Jacobson A, Deykin D, Matchar D. Managing oral anticoagulant therapy. Chest 2001; 119:22S-38S.

3 Doyle J, Turpie AJ, Hirsh J, Best C, Kinch D, Levine MN, Gent M. Adjusted subcutaneous heparin or continuous intravenous heparin in patients with acute deep vein thrombosis. Ann Intern Med 1987; 107: 441-445.

4 Landefeld CS, Goldman L. Major bleeding in outpatients treated with warfarin: incidence and prediction by factors known at the start of outpatient therapy. Am J Med 1989;87:144-152.

5 Beyth RJ, Quinn LM, Landefeld S. Prospective evaluation of an index for predicting the risk of major bleeding in outpatients treated with warfarin. Am J Med 1998;105:91-99.
Kuijer PMM, Hutten BA, Prins MH, Büller HR Prediction of the risk of bleeding during anticoagulant treatment for venous thromboembolism. Arch Intern Med 1999;159:457-460.

Wicki J, Perrier A, Perneger TV, Bounameaux H, Junod AF. Predicting adverse outcome in patients with acute pulmonary embolism: a risk score. Thromb Haemost 2000;84:548-552.

Zidane M, Scharm MT, Planken EW, Molendijk WH, Rosendaal FR, van der Meer FJM, Huisman MV. Frequency of major hemorrhage in patients treated with unfractionated intravenous heparin for deep venous thrombosis or pulmonary embolism. A study in routine clinical practice. Arch Intern Med 2000;160:2369-2373.

Wickramasinghe LSP, Bau SK, Bansal SK. Longterm oral anticoagulant therapy in elderly patients. Age Aging 1988;17:388-396.

0 Hylek EM, Singer DE. Risk factors for intracraneal hemorrhage in outpatients taking warfarin. Ann Intern Med 1994;120:897-902.
11 Nagge J, Crowther M, Hirsh J. Is impaired renal function a contraindication to the use of lowmolecular-weight heparin? Arch Intern Med 2002; 162:2605-2609

12 Hersh WR. Medical informatics: improving health care through information. JAMA 2002;288:19551958.

13 Fine LG, Keogh BE, Cretin S, Orlando M, Gould $\mathrm{MM}$, for the Nuffield-Rand Cardiac Surgery Demonstration Project Group. How to evaluate and improve the quality and credibility of an outcomes database: validation and feedback study on the UK Cardiac Surgery Experience. BMJ 2003; 326:25-28.

14 Black N. Using clinical databases in practice. BMJ 2003;326:2-3. 